Different treatment options exist for management and are applied according to the anatomy of the aneurysm and flow dynamics in the coronary circulation. Repeat coronary artery bypass grafting with aneurysmal excision is the classic approach. Reports have been published of successful stent placement when continued antegrade flow through the graft is necessary, and coil embolization and vascular plugs have been used in cases in which this is neither necessary nor desired. ${ }^{3,5}$ These can also be particularly useful in patients in whom the risk of bypass surgery is high and because a reoperation, although high risk, does not eliminate the pathologic process of the veins. Endovascular procedures also have risks, however, and our patient illustrates 1 of them. The risk of bleeding, particularly in coagulopathic patients, is real in these procedures.

Ultimately, the outcomes of SVG aneurysm repair depend on acute recognition of the pathologic features from high clinical suspicion, obtaining early diagnostic tests to rule it out, and fast decision making regarding the approach for repair. The stakes are even greater in patients with severe dilatation and/or evidence of aneurysmal leakage.

\section{CONCLUSIONS}

We have described a patient with a giant vein graft aneurysm complicated by a leak and pulmonary hemorrhage. This diagnosis should be suspected in patients remote from coronary artery bypass grafting who present with hemoptysis and can be confirmed by computed tomography angiography. Covered stents can be successfully used to exclude these aneurysms and should be deployed in a timely manner to preclude adverse outcomes.

We would like to thank Dr Frederic Scott Resnic for performing the case.

\section{References}

1. Almanaseer A, Rosman HS, Kazmouz G, Giraldo AA, Martin J. Severe dilatation of saphenous vein grafts: a late complication of coronary surgery in which the diagnosis is suggested by chest x-ray. Cardiology. 2005;104:150-6.

2. Hascoet S, Roncalli J, Galinier M. Voluminous pseudoaneurysm of a saphenous vein graft. Arch Cardiovasc Dis. 2010;103:133-4.

3. Topaz O. Giant aneurysms of saphenous vein grafts: management dilemmas and treatment options. Catheter Cardiovasc Interv. 2006;67:611-6.

4. Kumar A, Santana D, Jenkins LA. Closure of a giant saphenous vein graft aneurysm with embolization coil. Cardiol Res Pract. 2009;2009:748272.

5. Panetta CJ, Schneider W, Boller MA. Percutaneous management of a long saphenous vein graft aneurysm: a case report and review of literature. Cardiol Res Pract. 2009;2009:981292.

\title{
Simultaneous sternal reconstruction and tricuspid valve replacement in a patient with chronic osteomyelitis and absence of tricuspid valve
}

\author{
Byung Kwon Chong, MD, ${ }^{\mathrm{a}}$ Joon Bum Kim, MD, ${ }^{\mathrm{a}}$ and Tae Jin Yun, MD, PhD, ${ }^{\mathrm{b}}$ Seoul, Republic of Korea
}

Chronic sternal osteomyelitis is an uncommon complication of major cardiac surgery and carries significant morbidity and mortality. If this complication is accompanied by severe tricuspid valve (TV) regurgitation and right heart failure, the management is more challenging. We report the successful treatment of such a case by simultaneous TV replacement and sternal reconstruction.

\footnotetext{
From the Department of Thoracic and Cardiovascular Surgery ${ }^{\mathrm{a}}$ and Division of Congenital Cardiac Surgery, ${ }^{\text {b }}$ Asan Medical Center, University of Ulsan College of Medicine, Seoul, Republic of Korea.

Disclosures: Authors have nothing to disclose with regard to commercial support.

Received for publication March 27, 2012; accepted for publication May 7, 2012; available ahead of print June 11, 2012.

Address for reprints: Joon Bum Kim, MD, Department of Thoracic and Cardiovascular Surgery, Asan Medical Center, 88, Olympic-Ro 43-Gil, Songpa-Gu, Seoul 138-736, Republic of Korea (E-mail: jbkim1975@amc.seoul.kr).

J Thorac Cardiovasc Surg 2012;144:e16-8

0022-5223/\$36.00

Copyright (C) 2012 by The American Association for Thoracic Surgery

http://dx.doi.org/10.1016/j.jtcvs.2012.05.006
}

\section{CASE REPORT}

A 65-year-old woman with type 2 diabetes mellitus and hypertension was admitted because of painful swelling of the anterior chest wall. She had a history of ventricular septal defect closure 13 years previously. Nine days postoperatively, sternal wound revision was done because of a deep sternal infection. She was readmitted 7 months later with endocarditis of the TV caused by methicillin-resistant Staphylococcus aureus and underwent tricuspid valvectomy through a right thoracotomy approach. During the ensuing 13 years, she experienced 5 episodes of sternal infection, which were treated by soft tissue debridement and vacuum-assisted closure.

At the present evaluation, she complained of dyspnea equivalent to New York Heart Association functional class III with prominent neck vein engorgement. Her temperature was $38.1^{\circ} \mathrm{C}$. The sternal wound was disrupted to a depth of 3 to $4 \mathrm{~cm}$ with a purulent discharge. The laboratory findings included a leukocyte count of $16,000 / \mathrm{mm}^{3}(94.6 \%$ polymorphonuclear cells) and C-reactive protein of 21.13 

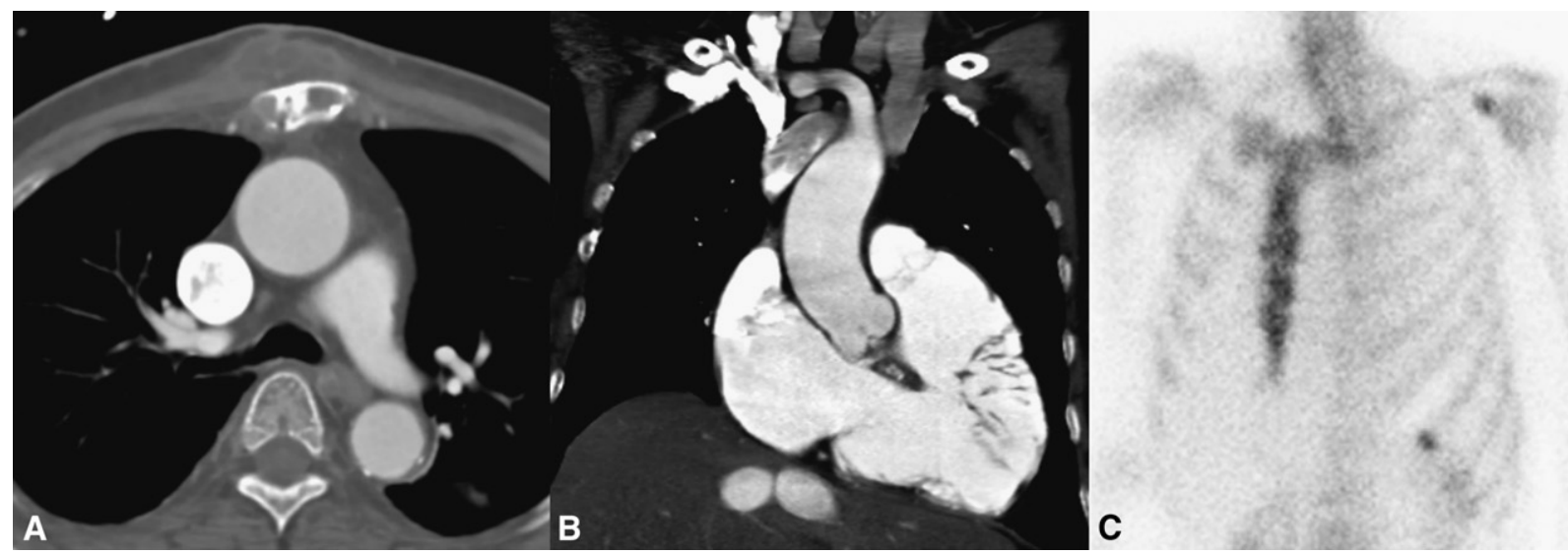

FIGURE 1. Preoperative enhanced computed tomography scan revealing (A) a deep soft tissue infection with abscess formation around the sternum, and (B) dilated right cardiac chambers without the tricuspid valve. C, Bone scan shows increased perfusion with delayed uptake in the sternum.

$\mathrm{mg} / \mathrm{dL}$. The pus cultures confirmed methicillin-resistant $S$ aureus. Computed tomography revealed a deep soft tissue infection with abscess formation around the sternum (Figure 1,A) and absence of the TV with right ventricular dilatation (Figure 1, B). Consistent with chronic osteomyelitis, the bone scan showed increased perfusion with delayed sternal uptake (Figure 1,C). Echocardiography revealed severe tricuspid regurgitation with a jet area of $20 \mathrm{~cm}^{2}$. We decided to perform total sternal resection and reconstruction with simultaneous TV replacement.

After skin incision at the previous sternotomy wound, the infected soft tissue was widely debrided. Repeat sternotomy was performed using an oscillating saw, after instituting cardiopulmonary bypass by way of femoral venous and arterial cannulation. After mediastinal adhesiolysis, another cannula was inserted into the superior vena cava. With a beating heart, TV replacement was performed using a mechanical prosthesis (On-X 31-mm; Medical Carbon Research Institute, Austin, Tex). After weaning from cardiopulmonary bypass, total sternal resection was done, and the skin incision was extended downward into the peritoneal space. The whole omentum was fully mobilized at the right gastroepiploic artery, and the omental pedicle was brought into the anterior mediastinum through a small diaphragmatic incision. The sternal defect was filled with the omentum, and 5 titanium plates were fixed horizontally to the corresponding costal cartilages using 2 or 3 screws on each side (Figure 2, $A$ and $B$ ). Bilateral pectoralis muscleadvanced flaps were interposed anterior to the titanium

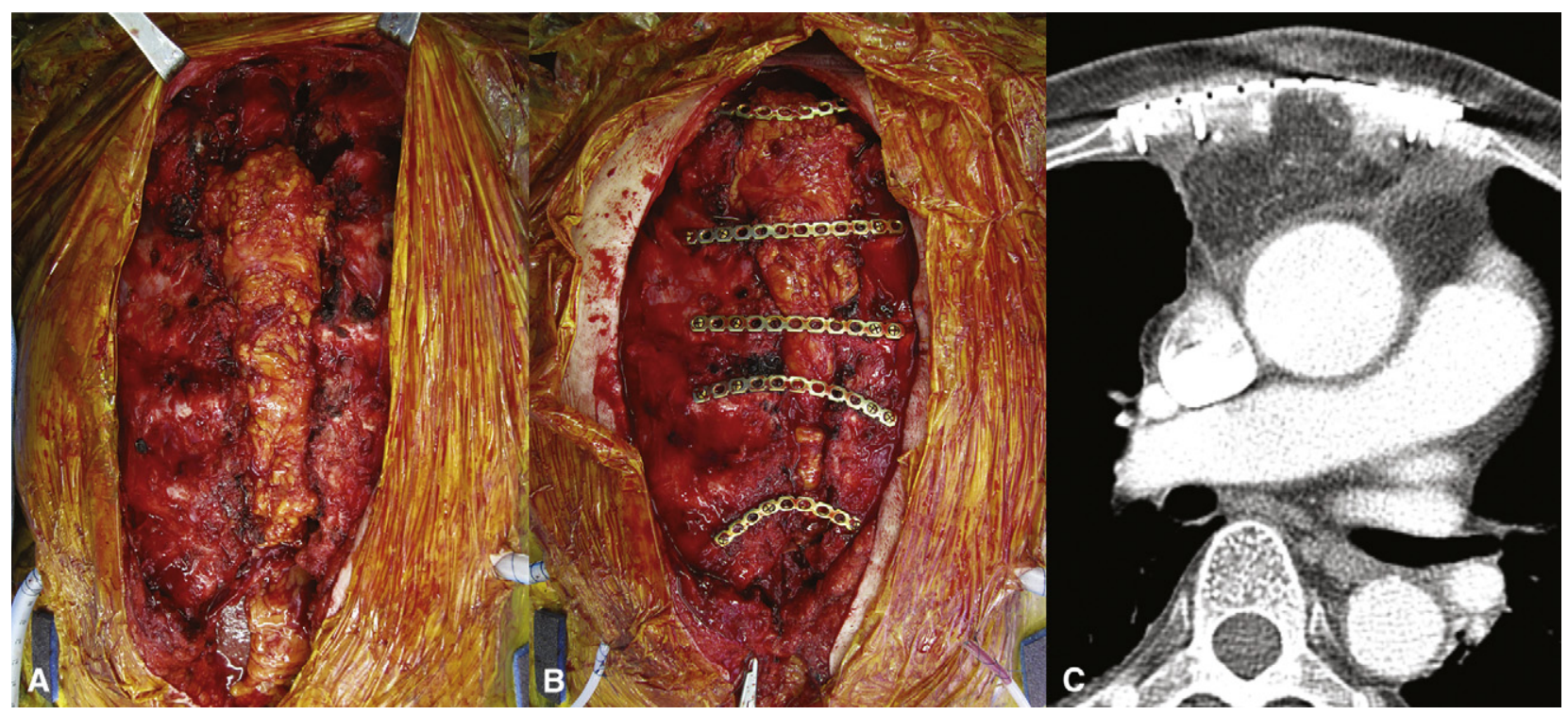

FIGURE 2. A, The omental flap fills the dead space after total sternal resection. B, Titanium plates are bridging the chest wall defect. C, Postoperative computed tomography scan showing well-maintained sternal integrity without signs of infection. 
plates. The chest was closed over 2 small drainage catheters placed under the pectoralis muscle.

The postoperative course was uncomplicated. On computed tomography performed on postoperative day 21 , sternal integrity was well maintained, without signs of infection (Figure 2, C). After completing 6 weeks of intravenous vancomycin therapy, she was discharged. The patient has been free of wound infections or heart failure symptoms for 6 months postoperatively.

\section{DISCUSSION}

Generally, eradication of sternal osteomyelitis requires radical debridement, sternectomy, and reconstruction of the chest wall. ${ }^{1}$ A comprehensive approach involving interposition of pedicled autologous tissue at the resected site to obliterate the dead space and fixation using multiple rigid plates to restore sternal integrity has been suggested as the ideal option for reconstructing the resected sternum in severe sternal infections. ${ }^{2,3}$

When such infections are combined with heart valvular pathologic features, several surgical approaches, either simultaneous or staged, can be considered. Staged sternal reconstruction followed by TV replacement through repeat sternotomy would have been impossible in the present case, because the titanium plates and hypervascular omental tissue would have blocked the way. Furthermore, the history of right thoracotomy will hinder an approach through this incision owing to the pleural adhesions. In contrast, valve replacement before managing the sternal osteomyelitis would have increased the risk of prosthetic endocarditis. ${ }^{4}$
Therefore, we decided on a simultaneous approach. Successful treatment of simultaneous heart valve disease and radiation-induced chest wall tumor has been reported with such a single-stage surgery. ${ }^{5}$ To the best of our knowledge, however, this is the first description of extensive sternal reconstruction combined with TV replacement for longstanding severe sternal infection. Using this aggressive approach, the chances of complications and time-consuming medical procedures might have been decreased, significantly reducing the patient's somatic and psychological stress.

\section{CONCLUSIONS}

For cases of sternal infection and concomitant cardiac valve pathologic features requiring surgery, a simultaneous approach combining valve surgery with radical resection of infected tissue and reconstruction using titanium plates and autologous tissue could be a reasonable surgical option.

\section{References}

1. Wettstein R, Erni D, Berdat P, Rothenfluh D, Banic A. Radical sternectomy and primary musculocutaneous flap reconstruction to control sternal osteitis. J Thorac Cardiovasc Surg. 2002;123:1185-90.

2. Gaetano R, Flavio F, Carmine LM, Antonello LR, Stefano M, Raffaele P, et al. Omental flap and titanium plates provide structural stability and protection of the mediastinum after extensive sternocostal resection. Ann Thorac Surg. 2010; 90:e14-6.

3. Athanassiadi K, Theakos N, Benakis G, Kakaris S, Skottis I. Omental transposition: the final solution for major sternal wound infection. Asian Cardiovasc Thorac Ann. 2007;15:200-3.

4. Sanfelippo PM, Danielson GK. Complications associated with median sternotomy. J Thorac Cardiovasc Surg. 1972;63:419-23.

5. Sachithanandan A, Dandekar U, Grimer R, Peart F, Rooney SJ. Aortic valve replacement with simultaneous chest wall reconstruction for radiation-induced sarcoma. J Card Surg. 2008;23:58-9.

\title{
Conservative management and resolution of iatrogenic type A aortic dissection in a patient with previous cardiac surgery
}

\author{
Tomasz A. Timek, MD, ${ }^{\mathrm{a}, \mathrm{b}}$ Robert Hooker, MD, ${ }^{\mathrm{a}, \mathrm{b}}$ Lawrence Patzelt, MD, ${ }^{\mathrm{a}, \mathrm{b}}$ and Gregory Bernath, MD, ${ }^{\mathrm{a}, \mathrm{c}}$ \\ Grand Rapids, Mich
}

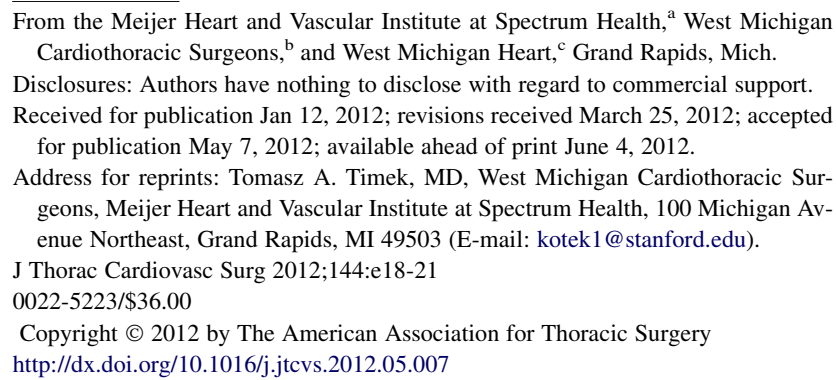

Treatment of iatrogenic acute type A aortic dissections (TAAD) remains controversial, with both surgical and percutaneous repairs advocated. We present the clinical course of a patient with previous cardiac surgery and catheterinduced acute iatrogenic TAAD that was successfully treated with conservative management.

\section{CASE REPORT}

A 55-year-old morbidly obese woman with a history of diabetes mellitus, tobacco abuse, dyslipidemia, and coronary artery disease treated twice by coronary artery bypass grafting in 2002 presented to an outside hospital 